\title{
Archéopages
}

Archéopages

Archéologie et société

42 | 04-07/2015

Construire en terre crue

\section{Constructions néolithiques en terre dans le Bassin parisien}

\section{Tony Hamon}

\section{(2) OpenEdition}

1 Journals

Édition électronique

URL : https://journals.openedition.org/archeopages/1132

DOI : 10.4000/archeopages. 1132

ISSN : 2269-9872

\section{Éditeur}

INRAP - Institut national de recherches archéologiques préventives

\section{Édition imprimée}

Date de publication : 1 mars 2016

Pagination : $20-21$

ISSN : $1622-8545$

\section{Référence électronique}

Tony Hamon, «Constructions néolithiques en terre dans le Bassin parisien », Archéopages [En ligne], 42 | 04-07/2015, mis en ligne le 01 juillet 2017, consulté le 02 juin 2021. URL : http:// journals.openedition.org/archeopages/1132; DOI : https://doi.org/10.4000/archeopages. 1132

Ce document a été généré automatiquement le 2 juin 2021.

(c) Inrap 


\title{
Constructions néolithiques en terre dans le Bassin parisien
}

\author{
Tony Hamon
}

1 Le site du Petit Perollet, découvert lors d'un diagnostic mené par l'Inrap sur la commune de Villeneuve-sur-Conie (Loiret) ${ }^{1}$ (Gay, 2013), est implanté sur une crête située à l'interfluve de deux vallées sèches d'environ cinq mètres de profondeur pour cinquante à cent mètres de largeur. Il est surtout localisé sur la crête et le versant sud d'une des deux vallées. Il se signale dans le paysage par une butte de moins de 1,5 m de hauteur et s'étend sur une surface estimée de près d'un hectare [ill. 1]; il semble qu'il soit entièrement compris dans l'emprise. D'après le mobilier récolté lors du diagnostic, il s'agit d'un site du Néolithique moyen (IV millénaire avant notre ère). 


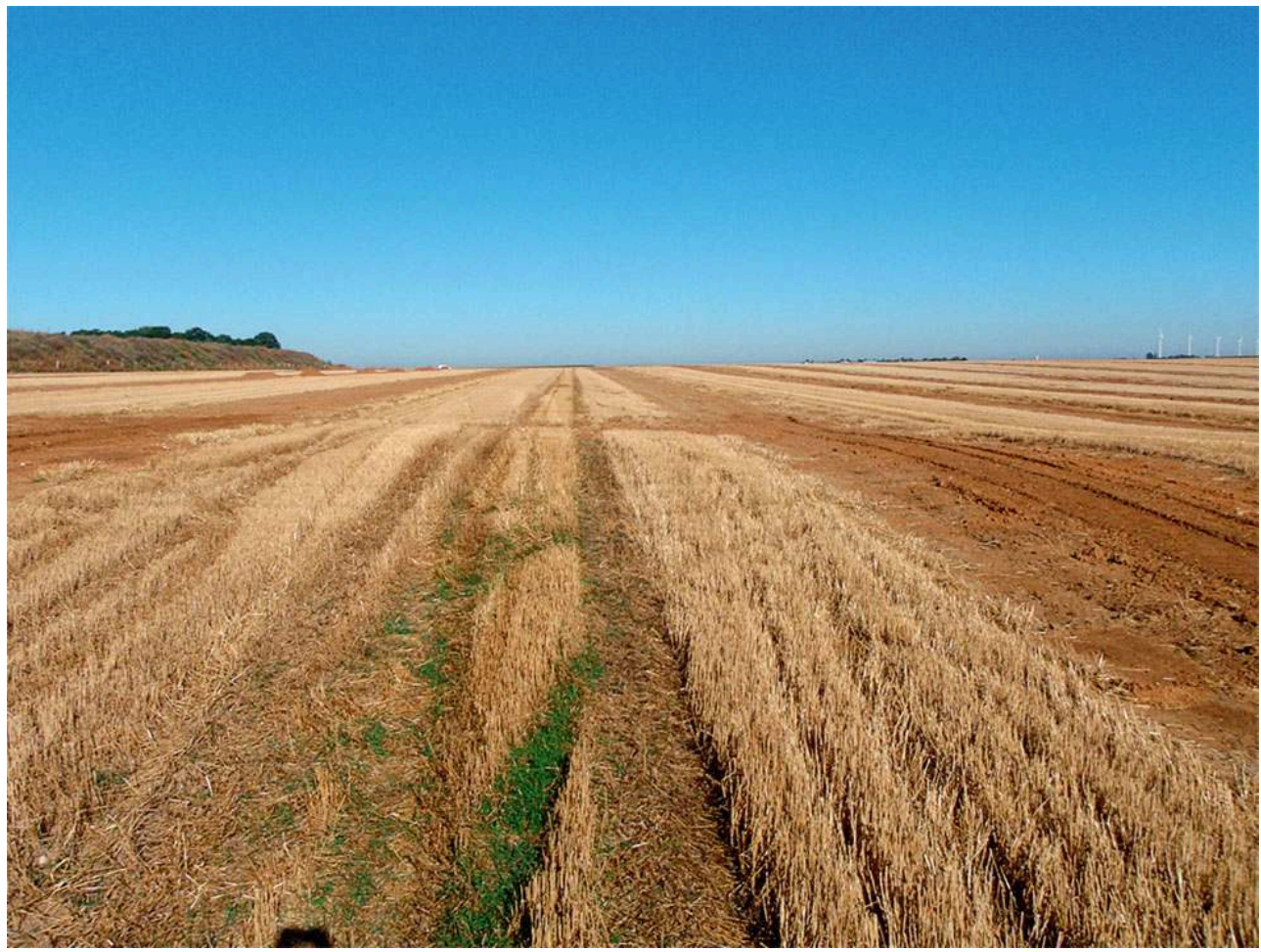

(c) J.-P. Gay, Inrap

2 La visite du site au moment de l'intervention, les relevés de terrain en plan et les clichés photographiques des coupes ont permis d'identifier deux phases de constructions en terre. Le niveau le plus ancien paraît avoir entièrement brûlé - c'est ce que laisse supposer la paroi externe rubéfiée sur une épaisseur d'environ $1 \mathrm{~cm}$ des bâtiments qui ont été reconnus. Identifiés dans un premier temps comme de la céramique dispersée sur le terrain, ces éléments ont été relevés en plan. Un sondage manuel réalisé dans une tranchée [ill.2] a permis de reconnaître les murs de deux bâtiments. Il s'agit de murs pignons (abside) prolongés chacun par un mur gouttereau. Lors du sondage manuel, les murs gouttereaux ont été fouillés par moitié depuis l'intérieur, tandis que les pignons ont seulement été sondés. Le sol intérieur n'a pas pu être atteint. Par ailleurs, trois assises de pains de terre massive au matériau épuré ont pu être observées en coupe [ill. 2]. Un autre bâtiment a également été identifié par des restes de murs visibles en décapage, à l'arrière de ces premiers éléments. En l'état, trois bâtiments au moins ont été reconnus pour la phase ancienne. 
2. Tranchée 1 - F1, vue en plongée du sud, de deux bâtiments en terre partiellement dégagés et sondés manuellement. Les parements extérieurs ont semble-il brûlé, ce qui expliquerait la présence de ces éléments rubéfiés. Les deux bâtiments semblent séparés par une rigole. Au second plan, un troisième bâtiment en coupe.

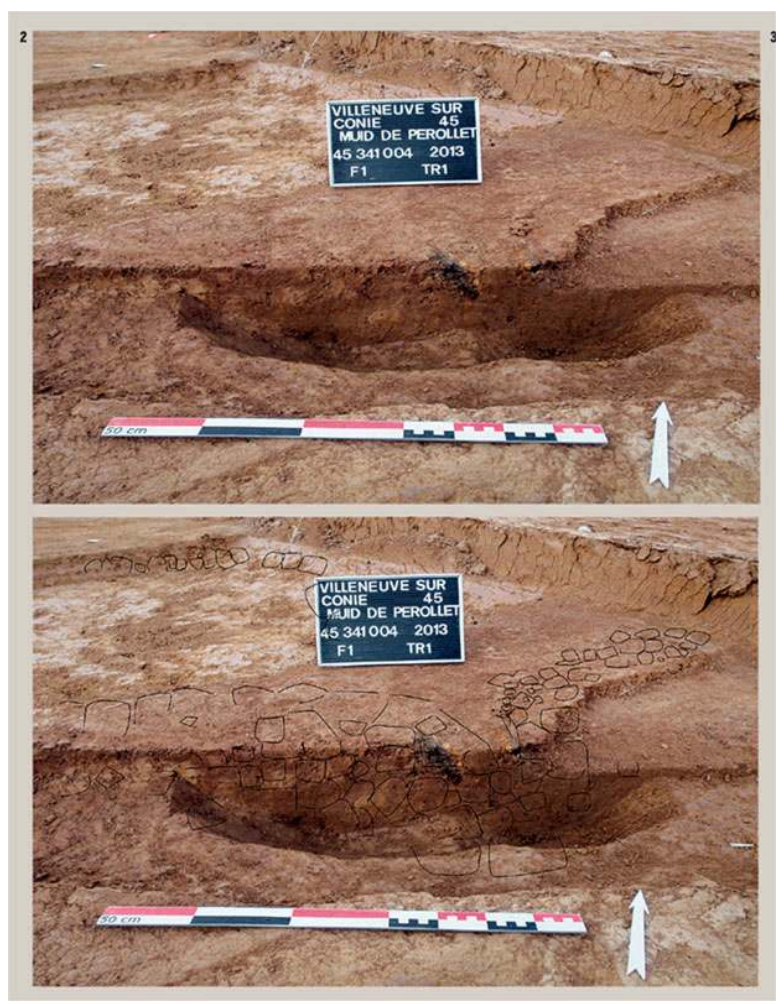

(C) C. Villenave, Inrap

3 Le niveau le plus récent présente des informations plus liminaires. En coupe, des pains de terre massive non brûlés ont été identifiés. Ce second niveau d'occupation a été en partie érodé par les labours modernes [ill. 3]. 
3. Tranchée 7 , détail de la stratigraphie dans ce secteur du site. Au moins trois niveaux de pains de terre sont visibles dans la coupe. De forme quadrangulaire, les modules sont variés. L'inclinaison de l'ensemble pourrait correspondre à l'effondrement d'un mur de terre à l'intérieur d'un bâtiment. Le substrat n'ayant pas été atteint à cet endroit, il n'est pas possible de dire si le site est installé sur le substrat calcaire.

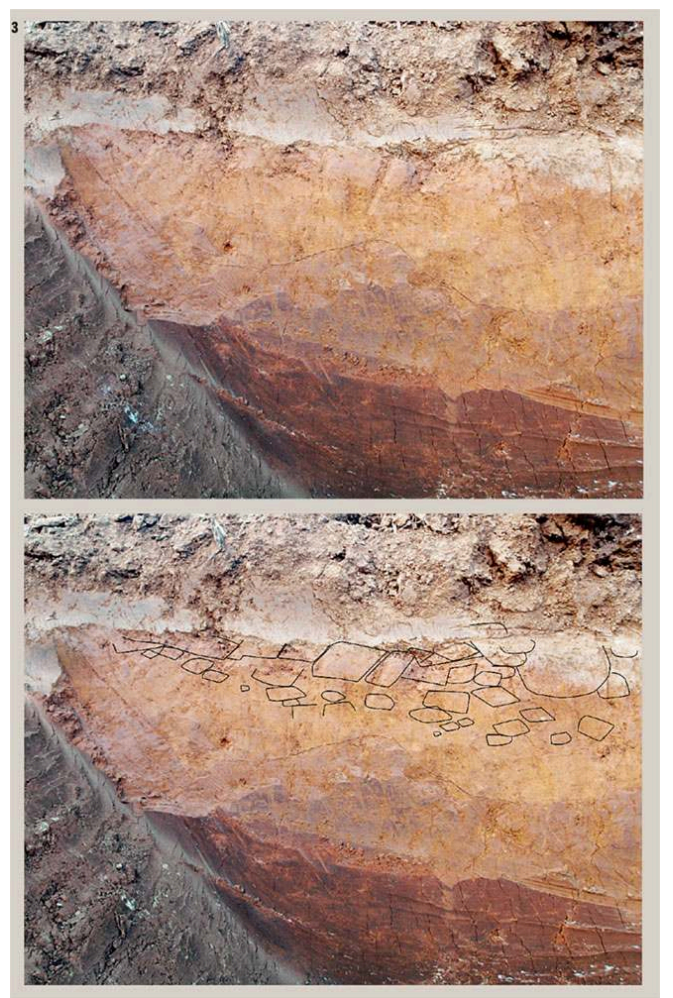

(c) C. Villenave, Inrap

4 D'après l'étude céramique (Gay, 2013), le mobilier, homogène, est attribué à la période 3 du Néolithique moyen entre 3900 et 3600 avant notre ère. Il s'agit donc actuellement d'une des plus anciennes traces de construction en terre massive néolithique dans le Bassin parisien. Par ailleurs, le niveau le plus ancien a livré des éléments sur l'architecture des bâtiments. Ainsi, suivant le sondage réalisé dans une des tranchées, les bâtiments comporteraient des croupes tandis que, sur d'autres relevés, des angles droits semblent se dessiner. Il se pourrait donc que, comme sur le site du Néolithique moyen de Lillemer (Ille-et-Vilaine) [encadré 2, p. 22], les bâtiments de Villeneuve-surConie comportent un pignon droit et une croupe. Cependant, à la différence de Lillemer, il ne s'agit pas d'un site de hauteur et il n'a pas été reconnu lors du diagnostic de limite matérialisant la périphérie du site. D'un point de vue méthodologique, enfin, le niveau incendié a offert la possibilité de dégager des éléments de bâtiments dans de bonnes conditions de visibilité, ce qui est rare.

On peut donc regretter que le diagnostic n'ait pas été suivi d'une prescription de fouille qui aurait permis d'approfondir nos connaissances sur ce site. À l'exemple de celui de Prasville, on ne peut que souhaiter que des interventions d'équipes pluridisciplinaires au fait du sujet se multiplient et que ces découvertes s'accroissant, cela conduise à la reconnaissance de ce type de sites dès le diagnostic. 


\section{BIBLIOGRAPHIE}

GAY J.-P. (dir.), 2013, Loiret (45), Villeneuve-sur-Conie, «le Muid de Pérollet », Rapport d'opération, Inrap-SRA Centre, $118 \mathrm{p}$.

\section{NOTES}

1. Fouilles du Muid de Pérollet menées sous la direction de J.-P. Gay, Inrap.

\section{AUTEUR}

TONY HAMON

Inrap, UMR 8215 « Trajectoires » 